\title{
A New Chart to Assist with Advanced Trauma Life Support
}

\author{
Maj I P Palmer
}

$M B, C h B, R A M C$

$\mathrm{SHO}$

c/o Queen Elizabeth Military Hospital, Stadium Road, Woolwich, London SE184QH

\section{P J F Baskett \\ FFARCS}

Consultant

Department of Anaesthetics, Frenchay Hospital, Bristol

\author{
SE McCabe* \\ FRCS \\ Senior Registrar \\ Accident \& Emergency Centre, Frenchay Hospital, Bristol
}

SUMMARY: Many studies have drawn attention to deficiencies in the management of major trauma, both in the UK and elsewhere. One area that has received little attention is the documentation of such cases in the Emergency Room. When outcome may be sub-optimal, documentation assumes greater importance if advances are to be made in the organisation of trauma care. Based upon the American College of Surgeons Advanced Trauma Life Support (ATLS) protocols, the authors have designed a document that records dynamically what happens to the multiply injured victim on arrival in the Emergency Room. It unifies the recording of vital signs, whilst acting as an assessment and resuscitation template. By ensuring no life-threatening illness is missed it is likely to improve patient survival. The document can act as a basis for teaching and a medico-legal record, whilst providing the necessary data for quality assurance and outcome audit.

\section{Introduction}

The problems associated with good management of the patient suffering from major injuries are legion (126) and short-comings in the UK service have been highlighted in the Royal College of Surgeons of England (RCS Eng) Working Party Report on the subject (1).

The particular problems in UK include:

1. A relatively low incidence of major trauma with the cases being admitted to a large number of hospitals. It is therefore difficult for any one individual or team to gain substantial personal experience.

2. Much of the management of major trauma which occurs, not only during the 'silent' hours (17000900), is left to junior trainees who have very little formal training, uneven experience and, for a variety of reasons, do not immediately seek the help of senior colleagues (2).

3. Poor documentaion compounds these problems, leading to inadequate and disorganised communication between medical staff in transferring hospitals and receiving centres, and between specialists within a given hospital. Scanty and inappropriate recording also precludes an adequate audit of trauma management and outcome. The same form of record may be used for a patient with an infected toe nail or a ruptured spleen.

*Now Consultant in Charge, Accident \& Emergency Department, Gloucestershire Royal Hospital, Great Western Road, Gloucester
We therefore set out to design recording charts fof patients with major injuries which would ensure relevank history taking, systematic patient assessment resuscitation and examination, plus a dynamic record of vital signs; investigation and therapy. This como prehensive information is presented so that it can be rapidly assimilated by those called to see the patient in the Emergency Department. It is also valuable for audit studies in individual cases, for teaching purposes and for research projects at a later date $(3,4,5)$.

The charts encourage the creation of a trauma team leader working along the protocols advocated in the Advanced Trauma Life Support (ATLS) Course designed by the American College of Surgeons and now adopted by the RCS Eng $(6,7,8)$.

The charts are designed to be simple, minimise longhand writing and duplication of information recording, while ensuring that items are not forgotten or missed on the examination and assessment, so encouraging a uniform standard of trauma care (9). This type of standardised approach has been used successfully by the Resuscitation Councils of the UK and Australia and the American Heart Association with flow charts for cardiopulmonary resuscitation (CPR) (6).

The nursing staff at Frenchay Hospital, Bristol were actively involved in the development and design of the charts which have been in constant use since 1989 in the A \& E Department of the hospital. Other centres have also used the form since this time. 


\begin{tabular}{|c|c|c|}
\hline DATE & NAME & AGE \\
\hline TIME OF INCIDENT & HISTORIANS & \\
\hline
\end{tabular}
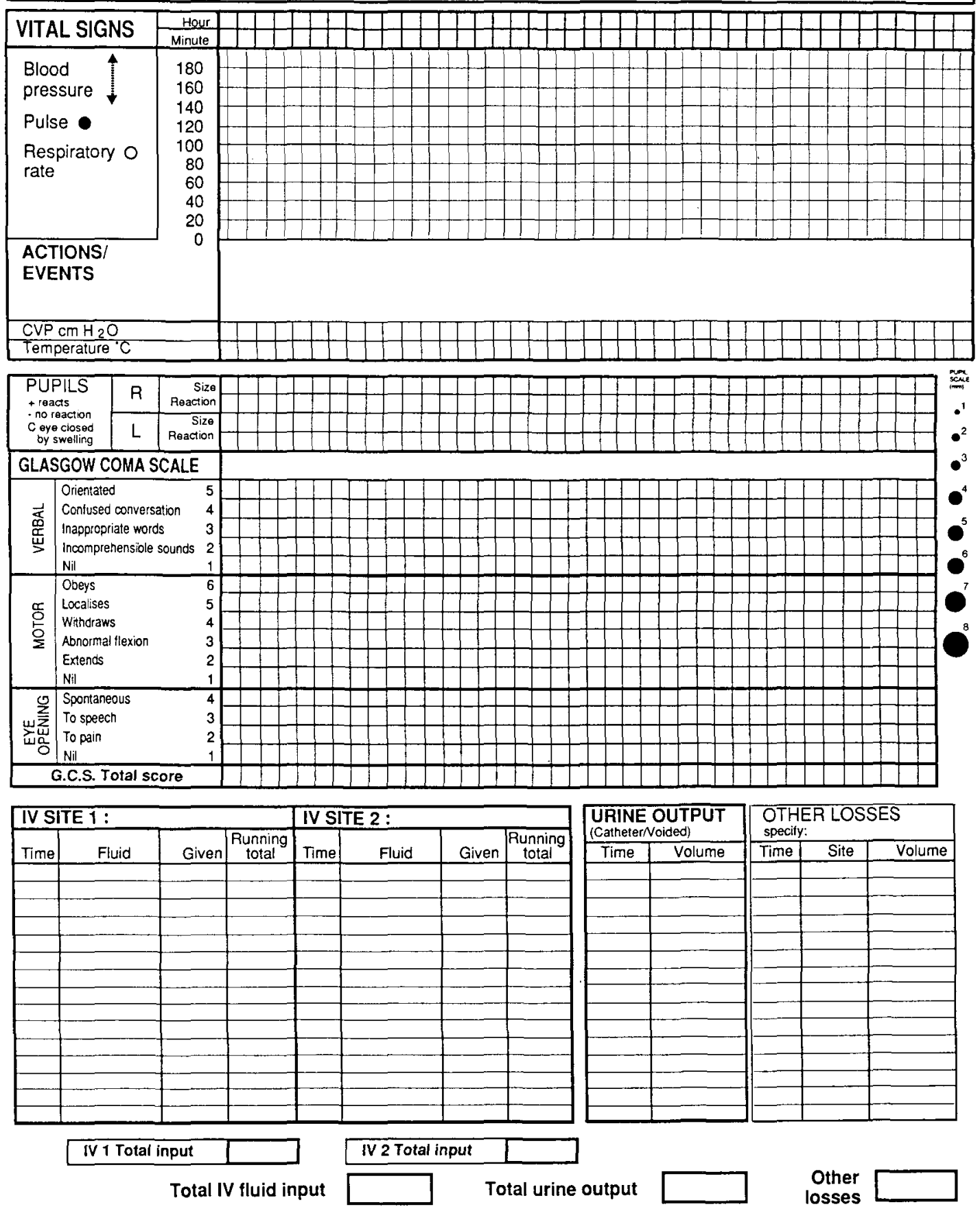


\begin{tabular}{|c|c|c|}
\hline AIRWAY & $\begin{array}{l}\square \text { NORMAL } \\
\square \text { UNCONSCIOUS } \\
\square \text { MAXILLO-FACIAL INJURY }\end{array}$ & $\begin{array}{l}\square \text { SPONTANEOUS - MasKOPANPACricoid ainway. } \\
\square \text { VENTILATED } \square \text { ETT (size — type } \\
\square \text { NASO-GASTRIC TUBE }\end{array}$ \\
\hline$\square$ C-SPINE & $\begin{array}{l}\square \text { NORMAL } \\
\square \text { POSSIBLE INJURY } \\
\square \text { LONG TRACT SIGNS }\end{array}$ & $\square$ FIRM COLLAR / SAND BAGS / IN-LINE TRACTION \\
\hline BREATHING & $\begin{array}{l}\square \text { NORMAL } \\
\square \text { TRAUMA } \\
\square \text { PNEUMOTHORAX (oluntpenetrating) } \\
\square \text { FLAIL SEGMENT } \quad \square \text { HAEMOTHORAX }\end{array}$ & $\begin{array}{l}\square \text { CHEST DECOMPRESSION / DRAINAGE } \\
\text { (Trocar Size _ Site } \\
\square \text { ABG }^{3}\end{array}$ \\
\hline$\square$ CIRCULATION & $\begin{array}{l}\square \text { NORMAL } \\
\square \text { HAEMORRHAGE } \square \text { REVEALED } \\
\square \text { CONCEALED } \square \text { chest } \\
\\
\square \text { abdomen } \\
\square \text { pelvis }\end{array}$ & 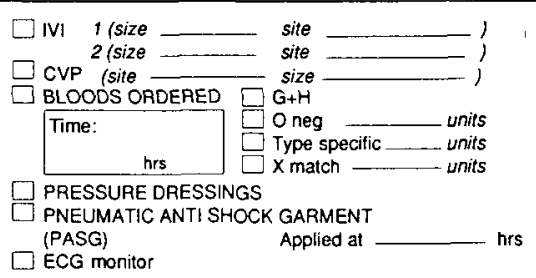 \\
\hline$\square$ DISABILITY & $\begin{array}{l}\square \text { NIL } \\
\square \text { POSSIBLE DAMAGE } \\
\square \text { LONG TRACT SIGNS }\end{array}$ & $\square$ FULL SPINAL CARE \\
\hline
\end{tabular}
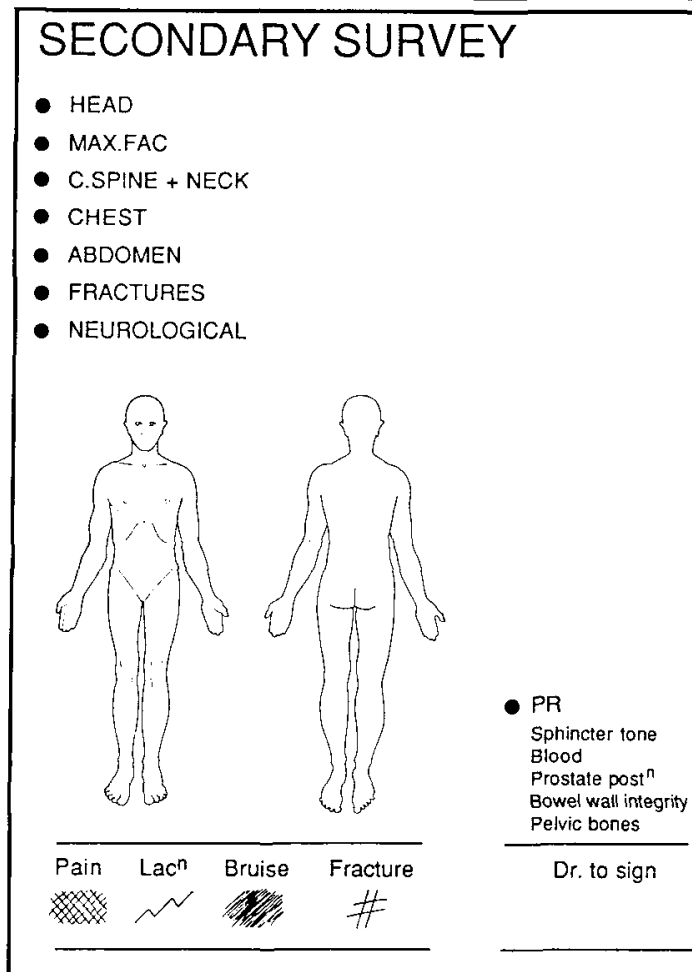

\begin{tabular}{|l|c|c|c|c|c|c|c|c|c|c|}
\cline { 2 - 10 } \multicolumn{1}{c|}{} & 4 & 3 & 2 & 1 & 0 & 4 & 3 & 2 & 1 & 0 \\
\hline Systolic BP & $>89$ & $76-89$ & $50-75$ & $1-49$ & 0 & $>89$ & $76-89$ & $50-75$ & $1-49$ & 0 \\
\hline Resp rate $\left(\min ^{-1}\right)$ & $10-29$ & $>29$ & $6-9$ & $1-5$ & 0 & $10-29$ & $>29$ & $6-9$ & $1-5$ & 0 \\
\hline Glasgow Coma Score & $13-15$ & $9-12$ & $6-8$ & $4-5$ & 3 & $13-15$ & $9-12$ & $6-8$ & $4-5$ & 3 \\
\hline TRAUMA SCORE & \multicolumn{3}{c|}{ On arrival } & & & On exit & \\
\hline
\end{tabular}

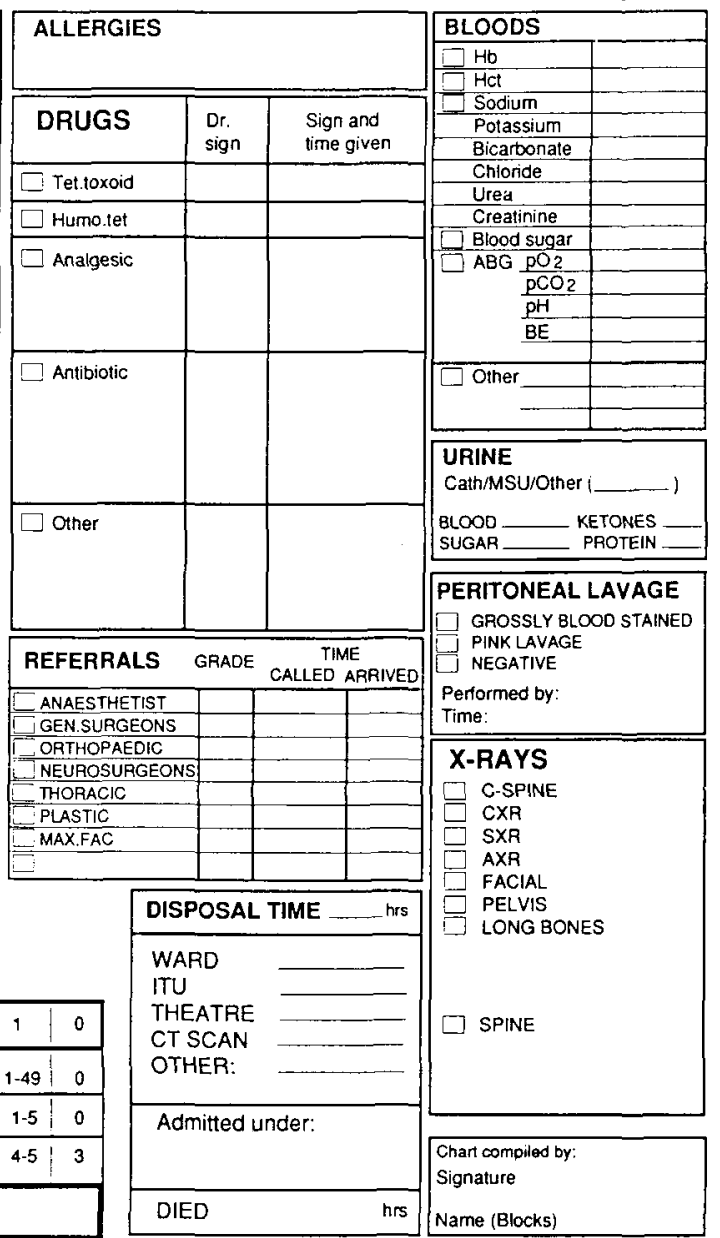

Grant assistance. HOECHST UK LTO HAEMACCEL (3)

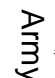

क

$\rho_{0}$

을

$\overrightarrow{\mathrm{B}}$

뭉

등.

$\frac{\bar{c}}{\bar{c}}$.

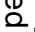

œ

$\overrightarrow{0}$

$\stackrel{\circ}{\longrightarrow}$

w.

.

ڤ్

$\vec{\omega}$

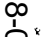

c.

.

윽

누

웅

बิ

बे

뭉

8

흥. 


\section{The Charts}

The chart records information in two separate parts:

\section{i. Chart A (observations):}

Figure 1. This section records observations of vital signs, essential personal information, the history of the injury and fluid balance (10).

ii. Cinart B (resuscitation):

Figure 2. This section records the primary survey and resuscitation, secondary survey, revised trauma score (RTS), results of special investigations, referral and disposal arrangements.

Chart A (observations, history and fluid balance) (Fig 1)

\section{i. Personal details and History}

Space is allocated for the patient's personal information and time of injury. Special emphasis is placed in recording the details of the incident, which may provide a quick guide to the nature and severity of the injury. A note is also made of any relevant medical history which may influence the response to the injury or treatment (10).

ii. Vital Signs

The record of vital signs (BP, pulse, respiratory rate, CVP, temperature, Glasgow Coma Scale and pupil size and responses) is collated on a single graph chart by time so that, for example, the effect of hypotension in a patient with a closed head injury can be easily observed.

It is from here that information is derived to allow the calculation of the RTS.

An actions/events box records interventions, investigations and treatment which serves particularly to relate invasive techniques with the ensuing vital signs, hopefully highlighting any harmful sequelae such as haemo/pneumothorax following insertion of a central line.

iii. Fluid Balance

There is ample space for fluid balance to be charted, even for the most severely injured patient.

This chart will be completed concurrently by the nursing staff whilst the medical attendant(s) undertake the primary survey, resuscitation and secondary survey $(6,8,9)$.

Chart B (resuscitation, surveys, investigations) (Fig 2)

\section{i. Frimary Survey and Resuscitation}

The first and foremost aim in any seriously injured patient is to make a brisk initial primary survey of the patient to estimate life threatening injuries along the ABCD protocols. This must be performed with "obsessional formality". No corners must ever be cut, and nothing else must be done until this survey is complete and appropriate resuscitation measures established to achieve stability of the vital functions. Accordingly the boxes for primary survey, assessment and resuscitative actions are at the top of the chart to emphasise their supreme importance.

This box serves to remind the physician of the primary survey examination procedure, the possible life threatening diagnosis and the steps required to ameliorate them. It is designed to ensure that vital steps are not omitted during the resuscitation phase, so reducing the number of tragic mistakes which contribute to avoidable trauma deaths $(11,12,13)$ e.g. the patient with a ruptured liver being incorrectly assessed and being taken to the operating room for relatively non-urgent orthopaedic surgery, and dying on the table from unsuspected massive haemorrhage.

It is of course essential to remember that a critically ill patient may become unstable at any time. The dynamic nature of the observation Chart $A$ allows rapid identification of the development of any such problems.

This survey and investigations, such as radiology, should not be performed until the patient is stabilised. Thus these boxes are situated in the lower half of the chart.

The secondary survey box contains a mannequin diagram and a brief reminder of the likely systems which may be injured.

iv. Investigations, Prescriptions, Disposal

The investigations to be ordered are conveniently blocked and serve as a reminder of possible injury and disruption of function.

The form also acts as a prescription chart minimising yet further the number of forms required for each patient. If recorded in the actions/ events box, any effects of prescribed drugs may be easily visualised by changes in the vital signs.

\section{Methods}

It proved impossible to gain access to retrospective records of those patients treated in the Resuscitation Area of the A \& E Department due to the constraints of time and changes of job.

A prospective study was undertaken over a period of 18 months (March 1989 - August 1990) on all "emergencies" treated in the Resuscitation Area of the hospital.

For the first 12 months (March 1989 - February 1990) the use of the forms were "encouraged", during the subsequent 6 months their use was deemed "mandatory".

\section{Discussion}

Table 1 reveals that the forms were being used for nontrauma cases. This was the innovation of the senior nursing staff who found the observation side (Figure 1) so useful that they extended its use to all unconscious patients etc.

The level of significance between the two periods for "Administrative Details" and "Vital Signs" was nonsignificant $\mathrm{p}>0.1$ throughout.

Tables 2 and 3, however, reveals significant improvement in levels of recording between Period 1 and 2 es- 
Table 1

The number of completed trauma forms.

\begin{tabular}{llc}
\hline & $\begin{array}{c}\text { Trauma } \\
\text { Cases }\end{array}$ & $\begin{array}{c}\text { Non- } \\
\text { Trauma } \\
\text { Cases }\end{array}$ \\
\hline $\begin{array}{l}\text { Period 1 12 months } \\
(3 / 89-2 / 90)\end{array}$ & 36 & 40 \\
$\begin{array}{l}\text { Period 2 6 months } \\
(3 / 90-8 / 90)\end{array}$ & 62 & 42 \\
\hline Totals & 98 & 82 \\
\hline
\end{tabular}

pecially in the use of the Revised Trauma Score (RTS) which has been shown, along with early reference to a more senior colleague, to be associated with improved

Table 2

The number of completed items on Figure 1.

\begin{tabular}{|c|c|c|}
\hline Trauma Cases Only & $\begin{array}{c}\text { Period } \\
1\end{array}$ & $\begin{array}{l}\text { Period } \\
2\end{array}$ \\
\hline Administrative Details & $\mathrm{n}=36$ & $\mathrm{n}=62$ \\
\hline Date & $34(94.4)$ & $58(93.5)$ \\
\hline Name & $35(97.2)$ & $60(96.7)$ \\
\hline Age & $33(91.6)$ & $52(83.8)$ \\
\hline Historian & $27(75.0)$ & $36(58.1)$ \\
\hline Incident Details & $35(97.2)$ & $57(91.9)$ \\
\hline Time of Arrival & $30(83.3)$ & $50(80.6)$ \\
\hline Time of Incident & $12(33.3)$ & $28(45.1)$ \\
\hline Time of Observations & $35(97.2)$ & $59(95.2)$ \\
\hline $\begin{array}{l}\text { Total Observations } \\
\text { made }\end{array}$ & \multicolumn{2}{|c|}{$241 / 288(84.7) 400 / 496(80.7)$} \\
\hline
\end{tabular}

Vital Signs

\begin{tabular}{lrr}
\hline B.P. & $35(97.2)$ & $56(90.3)$ \\
Pulse & $33(91.6)$ & $54(87.1)$ \\
Respiratory rate & $8(22.2)$ & $16(25.8)$ \\
Events/Actions & $15(41.6)$ & $16(25.8)$ \\
Pupils & $28(77.7)$ & $51(82.3)$ \\
Glasgow Coma Scale & $32(88.8)$ & $55(88.7)$ \\
IV Fluids & $23(63.8)$ & $44(70.9)$ \\
Output & $3(8.3)$ & $9(14.5)$ \\
C.V.P. & $1(2.7)$ & $1(1.6)$ \\
Temperature & $3(8.3)$ & $6(9.7)$ \\
B.M.Stix & $1(2.7)$ & $4(6.5)$
\end{tabular}

Total Observations

made

$182 / 396(46.0) 312 / 682(45.8)$
Table 3

The number of completed items on Figure 2.

Trauma

Cases Only

Period 1

Period 2

Resuscitation

Details

$\mathrm{n}=36$

$(\%)$

Signifi-

Primary Survey/

resuscitation

Secondary Survey

$22(61.1)$

$17(47.2)$

$55(88.7) \quad \mathrm{p}<0.005$

Revised Trauma

Score

$6(16.6)$

$\mathrm{X}$-Rays

$16(44.4)$

Bloods

$10(27.7)$

Drugs

$18(50.0)$

Disposal

$11(30.5)$

Referral

$10(27.7)$

Allergies

$1(2.7)$

$3(8.3)$

$47(75.8) \quad \mathrm{p}<0.01$

$40(64.5) \quad \mathrm{p}<0.00001$

48 (77.4) $\quad \mathrm{p}<0.005$

$31(50.0) \quad \mathrm{p}<0.05$

$33(53.0) \quad \mathrm{p}<0.01$

$38(61.3)$

39 (62.9) $\quad \mathrm{p}<0.005$

Urine

$7(11.3)$

8 (12.9)

Total Observations

made

$114 / 360(31.67) \quad 346 / 620(55.8) \quad \mathrm{p}<0.05$

patient care (14) and this is reflected in the juxtaposition $\frac{}{\mathbb{D}}$ of the RTS and the "Referrals" box.

The form should continue to evolve (Figs $3 \& 4$ ) and many departments have developed their own. How useful it would be to have a unified method of recording? what happens to the victims of trauma in our Casualtyo Departments.

\section{Conclusion}

This document offers a structured protocol designed to help medical staff faced with the daunting prospect of dealing with the multiply injured patient on an irregular basis, thereby enhancing their assessments whilst at the same time providing a "real time" record of what happens to a patient in his or her journey through the Casualty Department.

\section{Acknowledgement}

The evolution of this chart has taken much team work and we would like to recognise the following staff at Frenchay Hospital, Bristol: Sisters J Anderson, M Yeadon, L Hankey and A Lewis-Dickinson for their advice, help and encouragement in its design and use, and Dr John Capel, until recently Consultant in charge of the Accident Centre, for his encouragement. We should also like to thank Jane Fallows for the art work and many corrections required, and finally, for their generosity in supporting the art work and printing, Hoechst UK Ltd and Mr Cliff Wood. 
RESUSCITATION

\begin{tabular}{|c|c|c|c|}
\hline $\begin{array}{l}\text { PRIMARY } \\
\text { SURVEY }\end{array}$ & ASSESSMENT & & ACTIONS \\
\hline$\square$ AIRWAY & $\begin{array}{l}\square \text { UNCONSCIOUS } \\
\square \text { MAXILLO-FACIAL INJURY }\end{array}$ & $\square$ NORMAL & 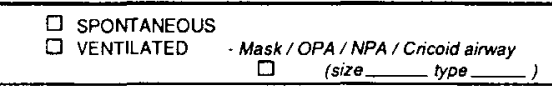 \\
\hline$\square$ C-SPINE & $\begin{array}{l}\square \text { POSSIBLE INJURY } \\
\square \text { LONG TRACT SIGNS }\end{array}$ & 口 NORMAL & F FIRM COLLAR/SAND BAGS/IN.LINE TRACTINN \\
\hline$\square$ BREATHING & $\begin{array}{l}\text { 口 TRAUMA rolunt/penetrating) } \\
\text { PNEUMOTHORAX (open/closed/ tension) } \\
\text { FLALL SEGMENT } \square \text { HAEMOTHORA) }\end{array}$ & $\square$ NORMAL & $\begin{array}{l}\text { CHEST DECOMPRESSION/ORAINAGE } \\
\text { (Trocar Size_ Site- } \\
\square \text { ABGs }\end{array}$ \\
\hline$\square$ CIRCULATION & $\begin{aligned} & \square \text { HAEMORRHAGE } \\
& \square \text { REVEALED } \\
& \square \text { CONCEALED } \\
& \\
& \square \text { chest } \\
& \square \text { abdomen } \\
& \square \text { pelvis } \\
& \square \text { CARDIAC TAMPONADE }\end{aligned}$ & D NORMAL & 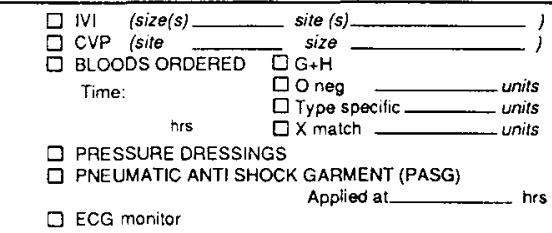 \\
\hline 口 Disability & $\begin{array}{ll} & \text { POSSIBLE DAMAGE } \\
\square & \text { LONG TRACT SIGNS }\end{array}$ & $\square$ Nil & $\square$ FULL SPINAL CARE \\
\hline
\end{tabular}

\begin{tabular}{|c|c|c|c|c|c|c|c|c|c|c|c|c|c|c|c|c|}
\hline & 4 & 3 & 2 & 1 & 0 & REFERRALS & GRADE & called & $\begin{array}{l}\text { ME } \\
\text { arrived }\end{array}$ & & 4 & 3 & 2 & 1 & 0 & ISS \\
\hline Systolic BP & $>89$ & $76-89$ & 50.75 & $1-49$ & 0 & A \& E Senior & & & & $S B P$ & $>89$ & 76.89 & $50-75$ & $1-49$ & 0 & \\
\hline Resp.rale $\mathrm{min}^{-1}$ & $10-29$ & $>29$ & 6.9 & $1-5$ & 0 & Anaesthetist & & & & $\mathrm{RR}$ & $10-29$ & $>29$ & $6-9$ & 1.5 & 0 & \\
\hline Glasgow Coma Score & 13-15 & $9-12$ & 6.8 & 4.5 & 3 & & & & & GCS & $13-15$ & 9-12 & 6.8 & 4.5 & 3 & \\
\hline $\begin{array}{l}\text { TRAUMA } \\
\text { SCORE }\end{array}$ & & a & rival & & & & & & & \multicolumn{2}{|c|}{$\begin{array}{l}\text { TRAUMA } \\
\text { SCORE }\end{array}$} & \multicolumn{2}{|c|}{ On exit } & & & \\
\hline
\end{tabular}

\section{SECONDARY SURVEY}

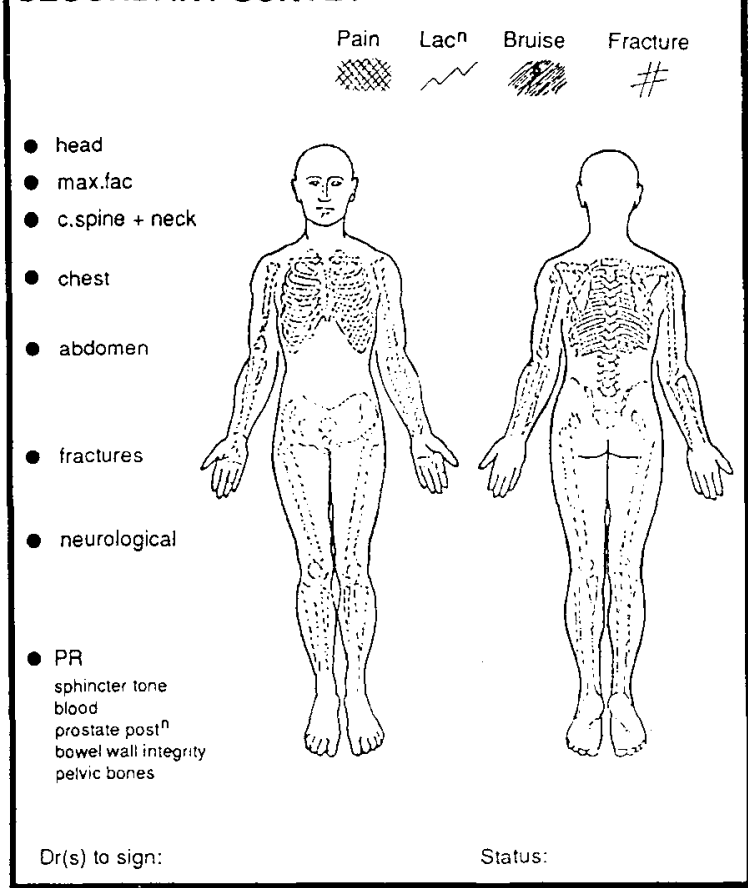

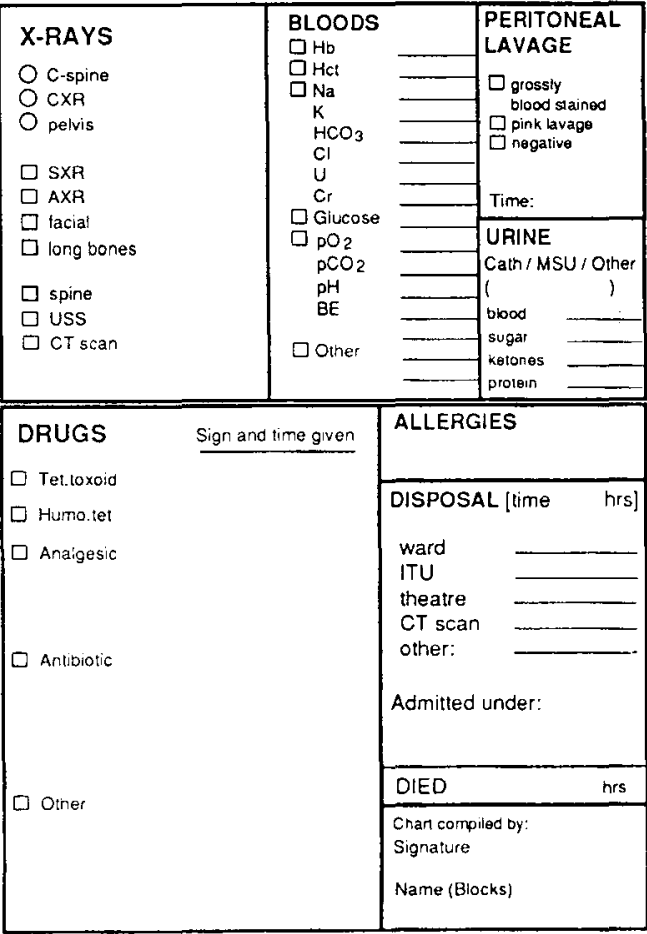

Fig 3. 


\section{HISTORY / OBSERVATIONS / FLUID BALANCE}

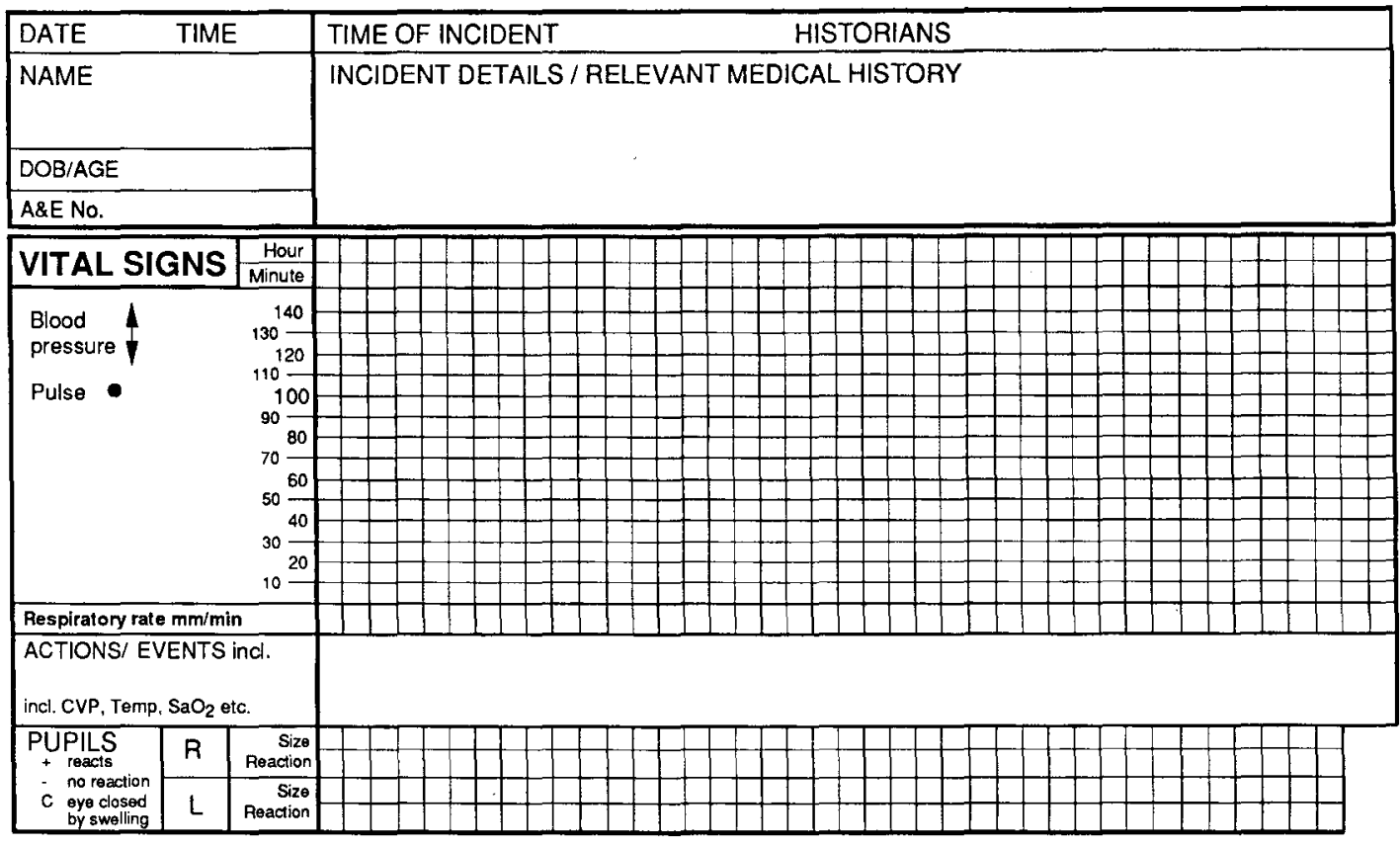

\begin{tabular}{|c|c|c|}
\hline \multicolumn{3}{|c|}{ GLASGOW COMA SCALE } \\
\hline 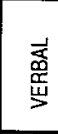 & $\begin{array}{l}\text { Orientated } \\
\text { Confused conversation } \\
\text { Inappropriate words } \\
\text { Incomprehensible sounds } \\
\text { Nil }\end{array}$ & $\begin{array}{l}5 \\
4 \\
3 \\
2 \\
1\end{array}$ \\
\hline $\begin{array}{l}\text { 똥 } \\
\frac{1}{\circ}\end{array}$ & $\begin{array}{l}\text { Obeys } \\
\text { Localises } \\
\text { Withdraws } \\
\text { Abnormal flexion } \\
\text { Extends } \\
\text { Nil } \\
\end{array}$ & $\begin{array}{l}6 \\
5 \\
4 \\
3 \\
2 \\
1\end{array}$ \\
\hline 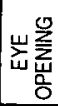 & $\begin{array}{l}\text { Spontaneous } \\
\text { To speech } \\
\text { To pain } \\
\text { Nil }\end{array}$ & $\begin{array}{l}4 \\
3 \\
2 \\
1\end{array}$ \\
\hline
\end{tabular}

G.C.S. Total score
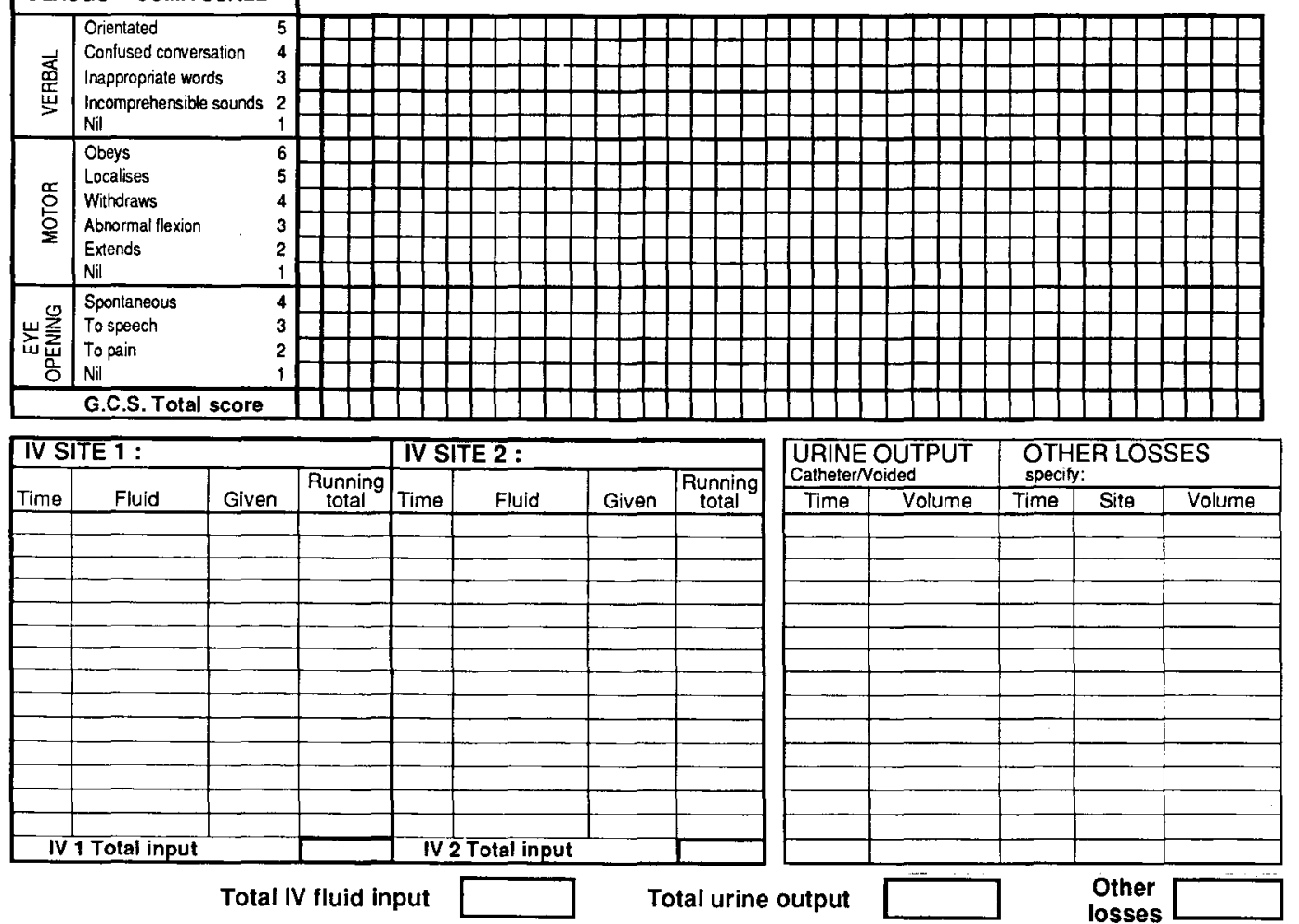

Total IV fluid input

Total urine output

Fig 4.

Other 


\section{REFERENCES}

1. Commission on the Provision of Surgical Services. Report of the Working Party on the Management of Patients with Major Injuries: Royal College of Surgeons of England 1988.

2. O'Byrne, G A, Bodiwalla G G. Use of the resuscitation room for trauma. Arch Emerg Med 1987; 4: 83-90.

3. Walters B C, McNeill I. Improving the record of patient assessment in the trauma room. $J$ Trauma 1990; 30 (4): 398-410.

4. Spence M T, Redmond A D, Edwards J D. Trauma Audit - the use of TRISS. Health Trends 1988; 3 (20): 94-7.

5. Malyi V K, Malyi Y V. Errors in the medical documentation of trauma patients. Sov Zdravookhr 1987; (12): 121-2.

6. Evans T R, ed. ABC of Resuscitation. BMA Books 1986.

7. Committee on Trauma. American College of Surgeons. ATLS Course Instructors Manual.

8. Hawkins $M$ L, Carraway R P, Laws H L. A protocol approach to the initial evaluation and treatment of multiple injured patients. Alaska Med 1986; 56 (4): 39-42.

9. Murat J E, Huten N, Mesny J. The use of standardised assessment procedures in the evaluation of patients with multiple injuries. Arch Emerg Med 1985; 2: 11-15.

10. Long W B, Bachulis B L, Hynes G D. Accuracy \& relationship of mechanisms of injury, trauma score $\&$ injury severity score in identifying major trauma. Ann J Surg 1986; 151 (5): 581-4.

11. GILROY D. Deaths from blunt trauma - a review of 105 cases. Injury 1984; 290: 1304-8.

12. Chan R N W, Ainscow D, Sikorski J M. Diagnostic failure in the multiple injured. $J$ Trauma 1980; 20: 684-7.

13. Trunkey D D, Lim R C JR. Analysis of 425 consecutive trauma fatalities. J Am Coll Emerg Phys 1974; 3: 368 .
14. Fisher R B, Dearden $\mathrm{C} H$. Improving the care of patients with major trauma in the accident and emergency department. $B r$ Med J 1990; 300; 1560-3.

15. Hawkins M L, Treat R C, Mansberger A R JR. The trauma score: a simple method to evaluate quality of care. Ann Surg 1988; B54 (4): 204-6.

16. Deane S A, Gaudry P L, Roberts R F, Juul O, LitTLE J M. Trauma triage - a comparison of the trauma score and the vital signs score. Aust $N Z J$ Surg 1986; 56 (3): 353-6.

17. Rhee K J, Willits N H, Turner J E, Ward R E. Trauma score change during transport: is it predictive of mortality? Ann J Emerg Med 1987; 5 (5): 353-6.

18. YATES D W. Leading article - action for accident victims. Br Med J 1988; 297: 1419-20.

19. Hoffman E. Mortality \& morbidity following road accidents. Ann R Coll Surg Eng 1976; 58: 233-40.

20. Yates D W. Airway patency in fatal accidents. $\mathrm{Br}$ Med J 1977; ii: 1249-50.

21. IRving M. Care of emergencies in the UK. Br Med J 1981 ; 283: 847-49.

22. ANDERSON I D, Woodford $M$, De Dombal $F T$, IRVING M. Retrospective study of 1000 deaths from injury in England and Wales. $\mathrm{Br}$ Med $J$ 1988; 290: 1305-8.

23. West J, TRUnKey D D, Lim R C. Systems of trauma care. Arch Surg 1979; 114: 455-60.

24. HAYWOOD I R. Training in immediate medical care. Care of the Critically Ill 1988; 4 (6): 23-4.

25. Roy $P$ D. The value of trauma centres: a methodological review. Can J Surg 1987; 30 (1): 1722.

26. OAKLEY $\mathbf{P}$ A. Inaccuracy and delay in decision making in paediatric resuscitation, and a proposal reference chart to reduce error. $\mathrm{Br} \mathrm{Med} J$ 1988; 2797: 817-9. 